ISSN 1112-9867

\title{
BLOCKING LAYER MODELING FOR TEMPERATURE ANALYSIS OF ELECTRON TRANSFER RATE IN QUANTUM DOT SENSITIZED SOLAR CELLS
}

\author{
M. J. Fahimi ${ }^{1}$, D. Fathi ${ }^{1, *}$ and H. Bastami ${ }^{2}$ \\ ${ }^{1}$ School of Electrical and Computer Engineering, Tarbiat Modares University (TMU), \\ Tehran, Iran, P.O. Box: 14115-194 \\ ${ }^{2}$ Technical and Vocational University
}

Published online: 15 May 2016

\begin{abstract}
In this article, we simulate thermal effects on the electron transfer rate from three quantum dots CdSe, CdS and CdTe to three metal oxides $\mathrm{TiO}_{2}, \mathrm{SnO}_{2}$ and $\mathrm{ZnO}_{2}$ in the presence of four blocking layers $\mathrm{ZnS}, \mathrm{ZnO}, \mathrm{TiO}_{2}$ and $\mathrm{Al}_{2} \mathrm{O}_{3}$, in a porous quantum dot sensitized solar cell (QDSSC) structure, using Marcus theory. We considered blocking layer as being on quantum dots and metal oxide, and we approximated quantum dots-blocking layer in the form of a sphere with new epsilon and radius. We import blocking layer effect in the Coulomb energies, which leads to the correct conduction band edges of the quantum dots and free energy of system and finally the Marcus equation. We obtained the results for the temperature range $400-250{ }^{\circ} \mathrm{K}$ which show that, increasing temperature for different combinations and blocking layers can give decreasing, increasing or decreasing-increasing trends. For $\mathrm{ZnO}-\mathrm{CdTe}$ combination, blocking layers $\mathrm{ZnO}, \mathrm{ZnS}, \mathrm{TiO}_{2}, \mathrm{Al}_{2} \mathrm{O}_{3}$ respectively, and for the other combinations, $\mathrm{ZnO}, \mathrm{TiO}_{2}, \mathrm{Al}_{2} \mathrm{O}_{3}$, $\mathrm{ZnS}$ respectively, have owned the highest rate. For verifying the simulation method, one of the experimental works performed by other researchers in the field of blocking layer was regenerated, that was in good agreement with our method with 3 percent error.
\end{abstract}

Author Correspondence, e-mail: d.fathi@modares.ac.ir

doi: http://dx.doi.org/10.4314/jfas.v8i3s.166 
The results obtained in this study can be better interpreted for empirical observations and also in the design and selection of MO-QD appropriate combinations in the presence of blocking layer in QDSSCs by considering the applied thermal effects.

Keywords: electron transfer rate; temperature; quantum dot; metal oxide.

\section{INTRODUCTION}

Quantum dot solar cells have emerged as Durable alternative to other third generation solar cells and solar cells organic pigments such as organic solar cells and large multi-layered pigments [Kamat, 2013, Kamat, 2012, Ruhle et al., 2010, Karmer and Sargent, 2011, Nozik, 2010, Hod and Zaban, 2013]. Quantum dots (QDs) in this structure are nanoscale semiconductor particle which their physical and chemical properties dependent upon the size [Jun et al., 2013, Choi et al., 2011, Jabbour and Doderer, 2010]. Nanocrystals or QDs such as CdS CdSe PbS PbSe PbSSe $\mathrm{CuInS}_{2} \mathrm{CuInSe}_{2} \quad \mathrm{CdSSe}$ and $\mathrm{CuInSe}_{\mathrm{x}} \mathrm{S}_{2-\mathrm{x}}$ are selected rather for use in quantum dot solar cells because of regulation of their energy gap in the visible and near-infrared regions [Baker and Kamat, 2009, Robel et al., 2006,Wang et al., 2011, Choi et al., 2009, Ma et al., 2009, Santra et al., 2013, Panthani et al., 2013,Santra and Kamat, 2013, MC Daniel et al., 2013]. In addition, some of these QDs have the ability to create multiple electron-hole pairs that this phenomenon causes the ability to increase the efficiency of the Shockley Kvayzr [Semonim et al., 2011, Stolle et al., 2014]. These cells rapid progress in recent years in increasing the efficiency have been reported yield less than $1 \%$ in 2005, 3\% in 2010, 5 percent in 2011, more than 7 percent in 2013 and now also more than 8 percent[Choi et al., 2011, Lan et al., 2014, Zhao et al., 2015, Mc Daniel et al., 2013]. In order to reduce the amount of electron-hole recombination in the quantum dot sensitized solar cells (QDSSC), a blocking layer is used in two modes: 1) blocking layer on the electrode to prevent electrons from returning the electrolyte to the electrode [Lan et al. , 2014, Seo et al. , 2011, Abbas et al. , 2015, Kin et al. , 2011, Meng et al. , 2014, Du et al. , 2014], 2) blocking layer on QDs (as a light-absorbing material) is used to reduce the returned electron from the QD to electrolyte or on the semi-conductor with large energy gap (as the electron collector) to prevent from returning electron to QDs valence band. Blocking layer also has a protective role inorder to prevention from corrosion QDs, metal oxides (MOs) and electrode against electrolyte [Zhao et al., 2015, Shen et al., 2008, Kang et al., 2015, Mora-Sero et al., 2009, Choi et al. , 2013, Yang et al., 2015, Zheng et al. , 2014, Jiao et al. , 2015, Bora et al. , 2012, Gonzalez-Pedro et al. , 
2010, Chang et al. , 2012, Chen et al. , 2011]. This layer plays an important role in enhancing the overall efficiency of the cell, so that in the year 2008, Shen et al. were able to use blocking layer $\mathrm{ZnS}$ deposited on $\mathrm{CdSe}$ quantum dots and $\mathrm{TiO}_{2}$ metal oxide increase their efficiency from 12.1 percent to 2/04 percent [Shen et al., 2008]. In 2009, Mora-Sero et al. were able to obtain officiency several times more than in absence of $\mathrm{ZnS}$ by using a $\mathrm{ZnS}$ blocking layer deposited on QDs and MOs [Mora-Sero et al. , 2009]. In 2011, Seo et al. could increase cell efficiency by nearly three times by using blocking layer TIP. [Seo et al., 2011]. Chang et al. in 2012 were able to use different combinations of blocking layers $\mathrm{ZnS}, \mathrm{ZnSe}$ and $\mathrm{Cu} 2 \mathrm{~S}$ to increase the efficiency from 0.53 to 2.52 percent [Chang et al. , 2012]. Santra et al. in 2013 could increase their efficiency from 1.14 to 3.91 percent by using CdS blocking layer [Santra et al., 2013].

In 2015, Zhao et al. by using separated $\mathrm{ZnS}$ and $\mathrm{SiO}_{2}$ blocking layers could extend efficiency from $2 / 53$ percent to $6 / 37$ percent and finally they were able to use a $\mathrm{ZnS} / \mathrm{SiO}_{2}$ combinational blocking layer to gain 21/8 percent of efficiency [Zhao et al., 2015]. It should be considered that in addition to the effect of blocking layer, various methods of depositing QD can also affect the efficiency of cells, so recently, Zhou et al. comparison and implementation of two methods of and CBD (Chemical Bath Deposition) and SILAR (Successive Ionic Layer Adsorption and Reaction) to depositing CdSe quantum dot on a layer of CdS (that plays the role of surface modification and pass electrons ), they could gain the 4/85 percent efficiency with the use of CBD that was much more than 3/89 percent efficiency by using SILAR [Zhou et al., 2015]. Kamat et al. have reported electron transfer rate between the QD and the $\mathrm{TiO}_{2}$ in the range of $10^{10} \sim 10^{11} 1 /$ s [Tvrdy et al., 2011, Chakrapani et al., 2011].

Since the electron transport process inside the porous layer of $\mathrm{TiO}_{2}$ is slower than the mechanism of electron transfer takes place, so losses due to recombination can be considered as an important factor in limiting the overall efficiency of cells [Tian and Cao, 2013], thus, using the blocking layer can play an important role in reducing the recombination and thus increase cell efficiency. By the investigations here, a new model for blocking layers is considered that the analysis of the effect of temperature parameter for various blocking layers is important.

In this study, we will simulate the effect of temperature in the presence of four commonly used blocking layer below, the electron transfer rate of three quantum dots $\mathrm{CdSe}, \mathrm{CdS}, \mathrm{CdTe}$ to three metal oxide $\mathrm{TiO}_{2}, \mathrm{ZnO}, \mathrm{SnO}_{2}$ based on Marcus theory.

1- [Choi et al., 2011, Sung et al., 2013] $\mathrm{Al}_{2} \mathrm{O}_{3}$, 
2- [Choi et al., 2013, Rao et al., 2015] ZnO,

3- [Kamat, 2008, Rao et al., 2015, Tachibana et al., 2008, Meng et al., 2015] $\mathrm{TiO}_{2}$

4- [Zhao et al., 2015, Shen et al., 2008, Mora-Sero et al., 2009, Chang et al., 2012, Lee et al., 2008] $\mathrm{ZnS}$. It should be considered that there is an obstacle with blocking layer for injecting electron from the transferor atom (QD) to the conduction band of acceptor electron (MO), and thus we will have a reduced rate of electron transmission blocking layer in comparison with the situation of without blocking layer. But due to reduced recombination (non-return of electron to the valence band QD) and an increase in the density of acceptor electron (due to placing the blocking layer on MO) [Rao et al., 2015], as shown in past work that mentioned above, blocking layer can ultimately increase the overall efficiency of the cell. To ensure accuracy of results, the electron transfer rate for a QDSSC sample construction work in the presence of a blocking layer reported in reference [Santra et al., 2013] were calculated by using our simulations, that with $3 \%$ error corresponded with the reported result.

\section{STRUCTURE, THEORY AND MODELING}

The considered structure is a QDSSC with porous structure that is shown in Figure 1 is along with transmission electron display, conduction band edge and the used semiconductor capacity in comparison of the vacuum.

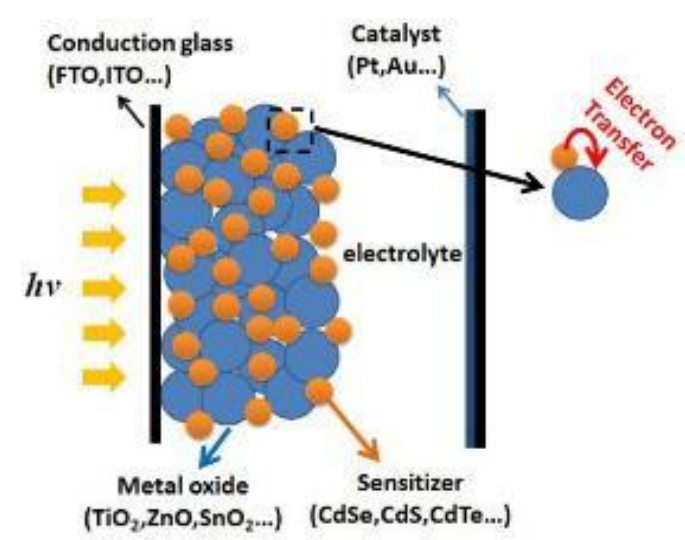

(a)

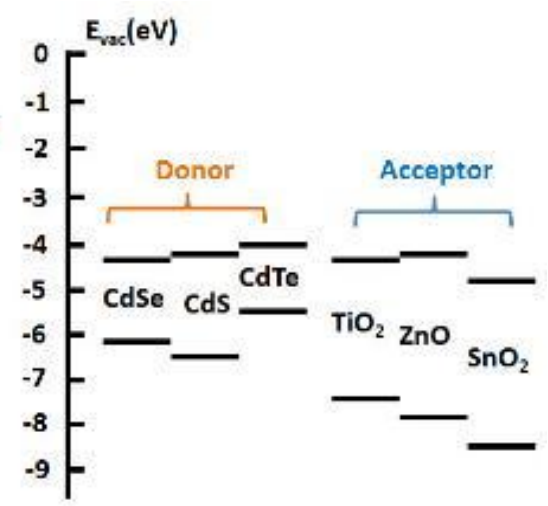

(b)

Fig.1. The considered structure without blocking layer with displaying electron transport from QD to MO (a), displaying position of the conduction energy band edges and the used semiconductor capacity (b) 
To calculate the electron transfer rate from QD to MO similar to Figure 1, you can use (Marcus Equation):

$$
k_{E T}=\frac{2 \pi}{\hbar} \int_{-\infty}^{+\infty} \rho(E)|\bar{H}(E)|^{2} \frac{1}{\sqrt{4 \pi \lambda k_{\mathrm{B}} T}} e^{-\frac{(\lambda+\Delta G+E)^{2}}{4 \lambda k_{\mathrm{B}} T}}
$$

where $k_{E T}$ is the electron transfer rate by $1 / \mathrm{sec}, \hbar$ is Planck's constant, $\rho(\mathrm{E})$ is density of states for $\mathrm{MO}, \bar{H}(E)$ is electronic coupling matrix between the acceptor electron and transferor electron, $\lambda$ is system rearrangement energy in $\mathrm{eV}, k_{\mathrm{B}}$ is Boltzmann constant, $\mathrm{T}$ is working temperature in Kelvin and $\Delta G$ is system free energy in eV. System free energy can be expressed as

$$
\begin{gathered}
\Delta G=\Delta G_{\text {coulomb }}+ \\
\Delta G_{\text {charging }}+\Delta G_{\text {electronic }}=E_{\mathrm{MO}}-E_{\mathrm{QD}}+\frac{e^{2}}{2 R_{\mathrm{QD}}}+2.2 \frac{e^{2}}{\varepsilon_{\mathrm{QD}} R_{\mathrm{QD}}}- \\
\frac{e^{2}}{4\left(R_{\mathrm{QD}}+h\right)} \frac{\varepsilon_{\mathrm{MO}}-1}{\varepsilon_{\mathrm{MO}}+1}
\end{gathered}
$$

where $E_{M 1}$ is $M O$ energy edge of the conduction band and $E_{1 S e}$ is QD energy edge of the conduction band compared to a vacuum, e is the charge of the electron, $\varepsilon_{\mathrm{QD}}$ is QD di-electric constant, $\varepsilon_{\mathrm{M} \text { I }}$ is di-electric constant of $\mathrm{MO}$ and $\mathrm{h}$ is the distance between the QD and MO. Density of states for MO with considering the crystal defect can be expressed as

$\rho_{D}(E)=\int_{0}^{+\infty} \rho\left(E^{\prime}\right) \frac{1}{\Delta \sqrt{2 \pi}} e^{-\frac{\left(E-E^{\prime}\right)^{2}}{2 \Delta^{2}}} d E^{\prime}$

where $m_{e}$ is the electron effective mass, $V_{o}$ is volume of a single cell for $\mathrm{MO}$ and $\rho\left(\mathrm{E}^{\prime}\right)$ is without defect MO density of states, Delta parameter (depending on the width of the crystal defect in MO density states) is considered $50 \mathrm{meV}$ [Tvrdy et al., 2011].

We has discussed the issue of calculating the electron transfer rate from QD to MO, Now to import the effect of blocking layer on the QD and MO (Figure 2), we act like this, that we propose the approximate model for the equivalent of a sphere / shell with a sphere with new radius and epsilon. 


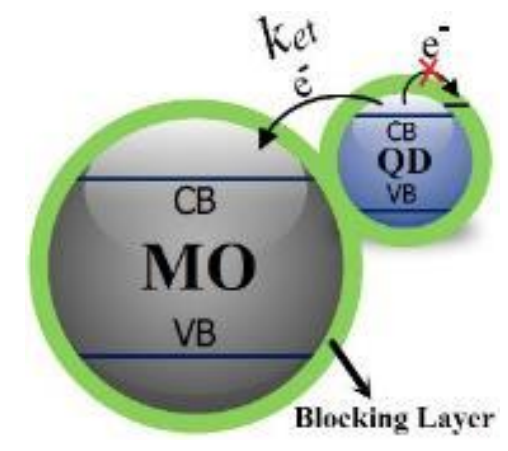

Fig.2. Displaying of the considered blocking layer on the QD and MO

In 2012, Mr. Chtyar and Anqta, proposed a model for a sphere / shell as a sphere with and new radial and proposed an equation for calculating the effective epsilon result of the layer on the sphere. Here we use this idea to approximate the effect of blocking layer in our structure.
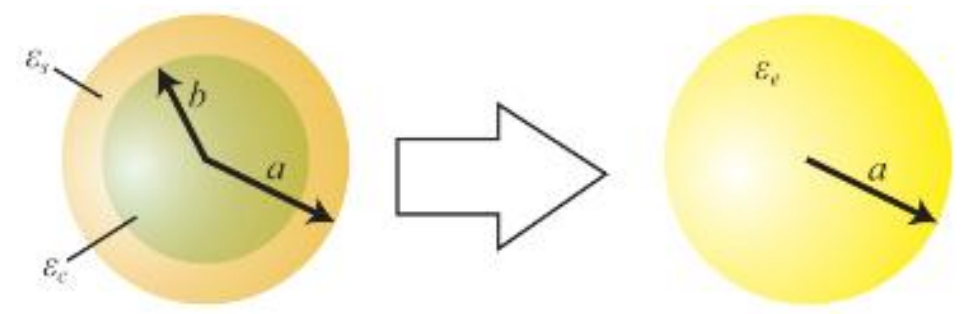

Fig.3. Equalization schematic of a semiconductor for sphere / shell into a sphere with new dielectric coefficient [Chettiar and Engheta, 2012]

New sphere achieved by a radius of "a" (sum of blocking layer thickness and QD radius), and effective new epsilon due to the blocking layer and the QD can be named dy $\varepsilon_{e}$. $\varepsilon_{e}$ with respect to Figure 3 can be calculated as:

$\varepsilon_{e}=\varepsilon_{s} \frac{a^{3}\left(\varepsilon_{c}+2 \varepsilon_{s}\right)+2 b^{3}\left(\varepsilon_{c}-\varepsilon_{s}\right)}{a^{3}\left(\varepsilon_{c}+2 \varepsilon_{s}\right)-b^{3}\left(\varepsilon_{c}-\varepsilon_{s}\right)}$

where $\varepsilon_{\mathrm{s}}$ is blocking layer dielectric constant (in this study, four blocking layer are used, $\mathrm{ZnS}$, $\mathrm{ZnO}, \mathrm{TiO}_{2}$ and $\left.\mathrm{Al}_{2} \mathrm{O}_{3}\right), \varepsilon_{\mathrm{c}}$ is dielectric constant $\mathrm{QD}, \varepsilon_{\mathrm{e}}$ is new effective dielectric constant for sphere, a and b, respectively are radius of the sphere / shell of radius QD [Chettiar and Engheta, 2012]. Table 2 indicates dielectric constant of 4 blocking layers. 
Table 1. Dielectric constant values of 4 blocking layers

\begin{tabular}{cc}
\hline Blocking layer & Epsilon \\
\hline $\mathrm{ZnS}$ & $8.3[$ Shevarenkov and Shchurov, 2006] \\
\hline $\mathrm{Al}_{2} \mathrm{O}_{3}$ & $9.4[$ Chin et al., 1999] \\
\hline $\mathrm{ZnO}$ & $9.9[$ Tvrdy et al., 2011] \\
\hline $\mathrm{TiO}_{2}$ & $10.5[$ Tvrdy et al., 2011] \\
\hline
\end{tabular}

Given the new epsilon for QD and MO we can calculate the rate using Marcus Equation 1, by modifying the system free energy (entering the new achieved epsilon in the Coulomb energies, electronic charges according to Eq. (2)). To enter the new epsilon effect in electronic energy, the Bruce Equation can be [Brus, 1986].

$$
E_{g(q d)}=E_{\mathrm{bulk}}+\frac{h^{2}}{8 R^{2}}\left[\frac{1}{m_{e} e^{*}}+\frac{1}{n_{h}^{*}}\right]-\frac{1.786 e^{2}}{4 \pi \varepsilon_{r} c_{0} R^{2}}
$$

where $E_{\text {bulk }}$ is energy gap for large-scale semiconductors, $\mathrm{R}$ is QD radius, $m_{e}$ and $m_{h}$ are effective mass of electrons and holes, respectively, $\varepsilon_{0}$ and $\varepsilon_{r}$ are vacuum permittivity constant and intended QD, respectively. We know that by increasing the temperature energy gap becomes small [Jeong et al., 2000, Caglar et al., 2010, Varshni, 1967], the effect of temperature in changing QDs and MO energy gap from testing charts can be approximated as Eq. 6. Here, the effect of this relationship is considered to see of temperature changes, in the atom conduction band edges changing and the acceptor electron [Singh and Ravindra, 2012, Donnel and Chen, 1991, Fahimi et al., 2015].

$E_{g(T)}=E_{\mathrm{g}\left(0^{\circ} \mathrm{K}\right)}-\frac{\alpha T^{2}}{\beta+T}$

$\alpha$ and $\beta$ coefficients in relation 6 can be achieved by matching the experimental plots. For CdSe and $\mathrm{CdS}$, these coefficients along with the energy gap for three QD and three MO, is given in Table 2, for other 4 semiconductor, is obtained from the test charts that displaying temperature dependence to the energy gap. 
As the free energy of the system implies, it shows new epsilon obtained in the Coulomb energy, and electronic charges (energy difference between conduction band edges of the two electron transferor atom and electron acceptor atom). Since the dimensions of MO compared to QD is much larger $(20 \mathrm{~nm})$, no noticeable change on conduction edge will be made. As a result, of the effect of blocking layer on it can be ignored and only its effect on the QD can be examine. Finally, regarding to the equation between temperature and energy gap in the electronic energy your and Marcus Equation, we could calculate results from 250 to $400{ }^{\circ} \mathrm{K}$ for 4 blocking layers on the electron transfer rate from QD to MO. Simulation constant parameters are considered as shown in Table 3 and the reference [Fahimi et al., 2015].

Table 2. The energy gap values for three QDs and three MOs used in the simulation with temperature parameters coefficients [Fahimi et al., 2015]

\begin{tabular}{|c|c|c|c|c|c|}
\hline Semi. & Eg(o $\kappa,(\mathrm{V})$ & $\begin{array}{l}\text { ac (ars coeffi } \\
\alpha \text { ev/ok) }\end{array}$ & $\begin{array}{l}{ }_{n}+\left(O_{[F a t}\right. \\
B \quad K)\end{array}$ & 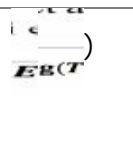 & $\begin{array}{l}\left.1 \leqslant{ }^{\circ} \mathrm{K}\right) \\
-E_{(O} g(T)\end{array}$ \\
\hline $\mathrm{CdSe}$ & 1.74 & $4.77 \times 10^{-4}$ & 295 & Eq. (6) & ----- \\
\hline $\mathrm{CdS}$ & 2.5825 & $3.06 \times 10^{-3}$ & 2156 & Eq. (6) & ------ \\
\hline $\mathrm{CdTe}$ & 1.595 & ----- & ------ & ----- & $1.64 \times 10^{-6} T^{2}$ \\
\hline $\mathrm{TiO}_{2}$ & 3.4 & ------ & ------ & ----- & $7 \times 10^{-4} T^{2}$ \\
\hline $\mathrm{ZnO}$ & 3.37 & ----- & ------ & ------ & $5.7 \times 10^{-6} T^{2}$ \\
\hline $\mathrm{SnO}_{2}$ & 3.8 & ----- & ------ & ------ & $8.12 \times 10^{-6} T^{2}$ \\
\hline
\end{tabular}


Table 3. Electron-hole effective mass values, epsilon and the used conduction band edges three MO and three QD [Fahimi et al., 2015]

\begin{tabular}{|c|c|c|c|c|}
\hline Semi. & $E^{c\left(e^{V}\right.}$ & $\varepsilon_{r}$ & $\mathrm{me}^{*}$ & $\mathbf{m}^{\mathbf{n}^{*}}$ \\
\hline $\mathrm{CdSe}$ & -4.4 & 6.23 & $0.13 \mathrm{~m}_{0}$ & $0.3 \mathrm{~m}_{0}$ \\
\hline $\mathrm{CdS}$ & -4.2 & 5.23 & $0.18 \mathrm{~m}_{0}$ & $0.53 \mathrm{~m}_{0}$ \\
\hline CdTe & -4.1 & 7.1 & $0.11 \mathrm{~m}_{0}$ & $0.35 \mathrm{~m}_{0}$ \\
\hline $\mathrm{TiO}_{2}$ & -4.41 & 9.9 & $\mathrm{~m}_{0}$ & not required \\
\hline $\mathrm{ZnO}$ & -4.36 & 10.5 & $0.2 \mathrm{~m}_{0}$ & not required \\
\hline $\mathrm{SnO}_{2}$ & -4.88 & 11.5 & $0.1 \mathrm{~m}_{0}$ & not required \\
\hline
\end{tabular}

\section{RESULTS}

We plotted the electron transfer rate for temperature ranges of 250 to $400{ }^{\circ} \mathrm{K}$ from QD to the MO, and for three QD and MO, and four cited blocking layers in 2 angstrom constant thickness of the blocking layer and $4 \mathrm{~nm}$ QD diameter. In general, we can see that the rate value respectively for blocking layer $\mathrm{ZnO}, \mathrm{TiO}_{2}, \mathrm{Al}_{2} \mathrm{O}_{3}$ and $\mathrm{ZnS}$ for all compounds except that the composition of the $\mathrm{ZnO}-\mathrm{CdTe}$, blocking layer of $\mathrm{ZnO}, \mathrm{ZnS}, \mathrm{TiO}_{2}, \mathrm{Al}_{2} \mathrm{O}_{3}$ had the highest rate, respectively (blocking layer $\mathrm{ZnS}$ had better behavior in comparison with the blocking layer $\mathrm{TiO}_{2}$ and $\mathrm{Al}_{2} \mathrm{O}_{3}$ in the electron transfer rate).

As shown in Figure 4 and 6 to the left, for combinations of $\mathrm{TiO}_{2}-\mathrm{CdSe}$ and $\mathrm{SnO}_{2}-\mathrm{CdSe}$ in this range of temperature changes, we will have a rate increase for a combination of $\mathrm{ZnO}-\mathrm{CdS}$ and $\mathrm{SnO}_{2}-\mathrm{CdSe}$, according to middle Figures 5 and 6 . First, we will have the rate increases by increasing temperature and then, by further thermal effects, the rate value will be reduced. For other 5 combinations of Figures 4-6, rate behavior by increasing temperature causes reduced rate. In fact, if the effects of temperature cause the more difference between the conduction band 
edges QD and MO, we will have a rate increase. Otherwise, by reduction the gap between the two conduction band edge, the rate will be reduced.
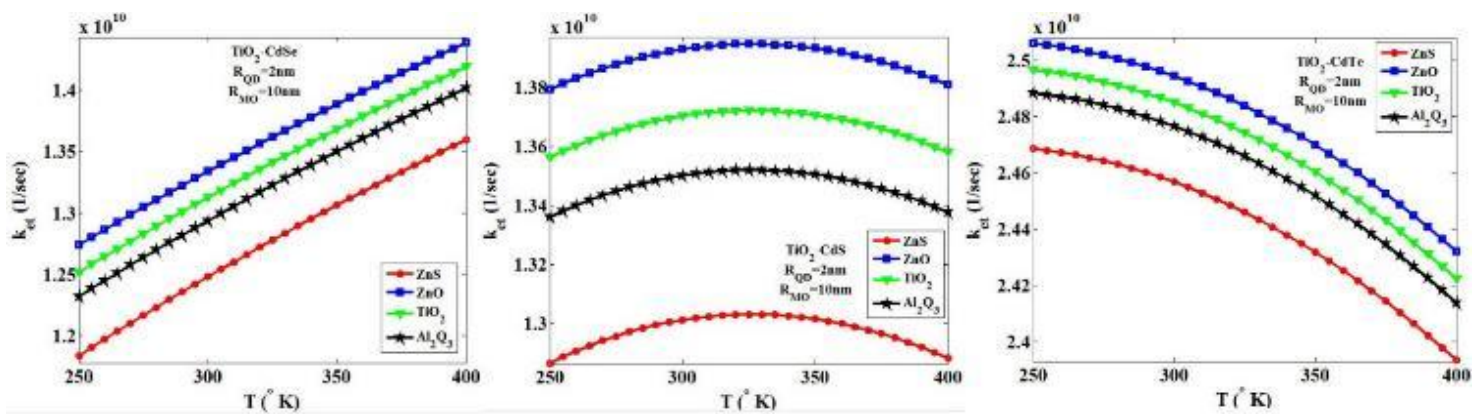

Fig.4. The electron transfer rate versus temperature changes from 250 to $400{ }^{\circ} \mathrm{K}$ for metal oxide $\mathrm{TiO}_{2}$, with 3 quantum dots $\mathrm{CdSe}, \mathrm{CdS}$, and CdTe with 4 blocking layers
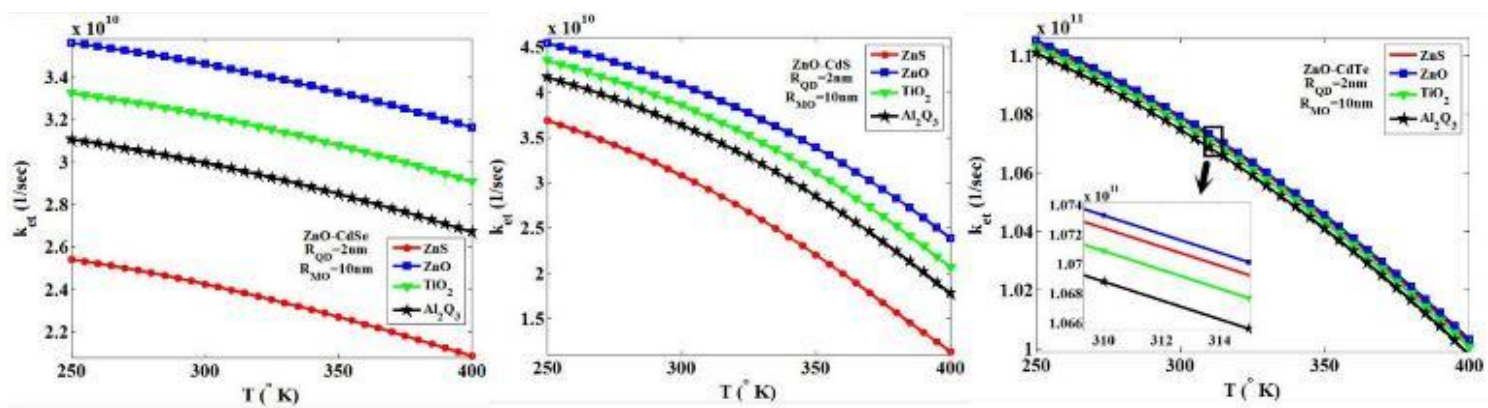

Fig.5. The electron transfer rate versus temperature changes from 250 to $400^{\circ} \mathrm{K}$ for metal oxide $\mathrm{ZnO}_{2}$ with 3 quantum dot $\mathrm{CdSe}, \mathrm{CdS}$ and CdTe with 4 blocking layers
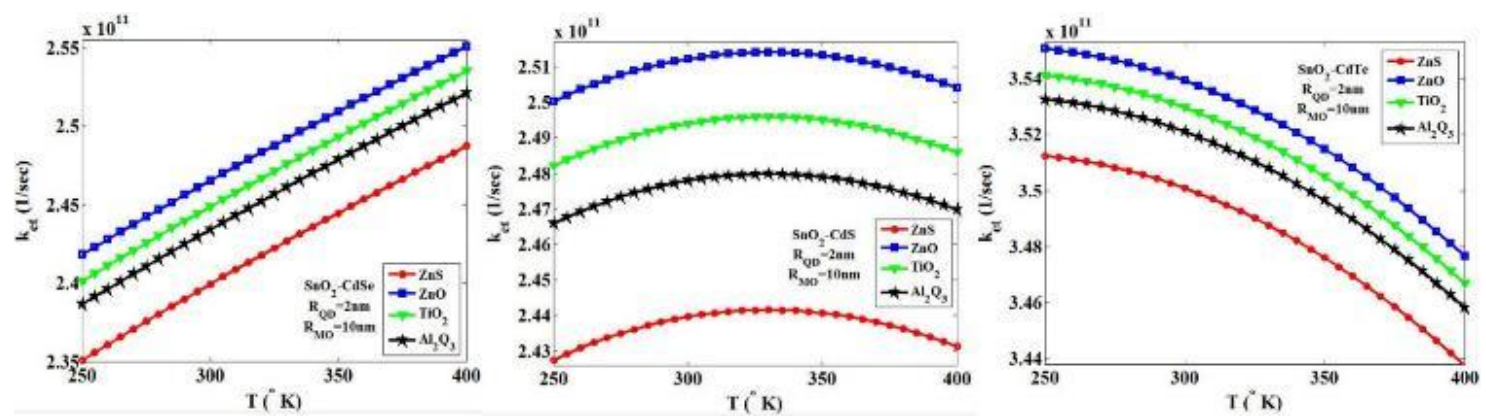

Fig.6. The electron transfer rate versus temperature changes from 250 to $400^{\circ} \mathrm{K}$ for metal oxide $\mathrm{SnO}_{2}$ with 3 quantum dot $\mathrm{CdSe}, \mathrm{CdS}$ and CdTe with 4 blocking layers 


\section{CONCLUSION}

Given the importance of blocking layer in efficiency, have been forced us in this paper with new presented model, to get the effect of this layer temperature on the layer by examining the important parameters in the electron transfer rate from QD to MO to achieve the highest rate in various combinations, and presented it to experience working. In this study, we have analyzed temperature changes from 250 to $400^{\circ} \mathrm{K}$ degrees in the presence of 4 commonly used blocking layer $\mathrm{ZnS}, \mathrm{ZnO}, \mathrm{TiO}_{2}$ and $\mathrm{Al}_{2} \mathrm{O}_{3}$, three quantum dots $\mathrm{CdSe}, \mathrm{CdS}$, CdTe and three metal oxide $\mathrm{TiO}_{2}, \mathrm{ZnO}_{2}, \mathrm{SnO}_{2}$. Intended blocking layer here, is on MO and QD. Due to the large MO dimensions, we ignored the effect of blocking layer, just only considered its effect on the QD. We assumed QD with blocking layer in the form of an effective sphere, and by calculating the new epsilon and radial and entering this two in Coulomb energy, we modified free energy system by entering charge and electronic between MO-QD, and finally the rate is calculated. Our results show that depending on the kinds of MO-QD combination, increased temperature could increase or decrease the electron transfer rate, and in some cases, an increase after certain temperature reduces the rate, and considering this, can halp experience working in the solar cells. To insure the way of simulation, the rate value for another QDSSC sample construction work in the presence of the blocking layer, was equal with the used method here with 3 percent error.

\section{REFERENCES}

[1] Kamat, P. V. (2013). Quantum dot solar cells. The next big thing in photovoltaics. The Journal of Physical Chemistry Letters, 4(6), 908-918.

[2] Kamat, P. V. (2012). Boosting the efficiency of quantum dot sensitized solar cells through modulation of interfacial charge transfer. Accounts of chemical research, 45(11), 1906-1915.

[3] Rühle, S., Shalom, M., \& Zaban, A. (2010). Quantum-dot-sensitized solar cells. ChemPhysChem, 11(11), 2290-2304.

[4] Kramer, I. J., \& Sargent, E. H. (2011). Colloidal quantum dot photovoltaics: a path forward. Acs Nano, 5(11), 8506-8514.

[5] Nozik, A. J. (2010). Nanoscience and nanostructures for photovoltaics and solar fuels. Nano letters, 10(8), 2735-2741.

[6] Hod, I., \& Zaban, A. (2013). Materials and interfaces in quantum dot sensitized solar cells: challenges, advances and prospects. Langmuir, 30(25), 7264-7273. 
[7] Jun, H. K., Careem, M. A., \& Arof, A. K. (2013). Quantum dot-sensitized solar cellsperspective and recent developments: A review of $\mathrm{Cd}$ chalcogenide quantum dots as sensitizers. Renewable and Sustainable Energy Reviews, 22, 148-167.

[8] Choi, H., Nicolaescu, R., Paek, S., Ko, J., \& Kamat, P. V. (2011). Supersensitization of CdS quantum dots with a near-infrared organic dye: toward the design of panchromatic hybridsensitized solar cells. ACS nano,5(11), 9238-9245.

[9] Jabbour, G. E., \& Doderer, D. (2010). Quantum dot solar cells: the best of both worlds. Nature Photonics, 4(9), 604-605.

[10] Baker, D. R., \& Kamat, P. V. (2009). Photosensitization of $\mathrm{TiO} 2$ nanostructures with CdS quantum dots: particulate versus tubular support architectures.Advanced Functional Materials, 19(5), 805-811.

[11]Robel, I., Subramanian, V., Kuno, M., \& Kamat, P. V. (2006). Quantum dot solar cells. Harvesting light energy with CdSe nanocrystals molecularly linked to mesoscopic $\mathrm{TiO} 2$ films. Journal of the American Chemical Society, 128(7), 2385-2393.

[12]Wang, X., Koleilat, G. I., Tang, J., Liu, H., Kramer, I. J., Debnath, R., ... \& Sargent, E. H. (2011). Tandem colloidal quantum dot solar cells employing a graded recombination layer. Nature Photonics, 5(8), 480-484.

[13] Choi, J. J., Lim, Y. F., Santiago-Berrios, M. E. B., Oh, M., Hyun, B. R., Sun, L., ... \& Hanrath, T. (2009). PbSe nanocrystal excitonic solar cells. Nano letters, 9(11), 3749-3755.

[14] Ma, W., Luther, J. M., Zheng, H., Wu, Y., \& Alivisatos, A. P. (2009). Photovoltaic Devices Employing Ternary PbS x Se1-x Nanocrystals. Nano letters, 9(4), 1699-1703.

[15] Santra, P. K., Nair, P. V., George Thomas, K., \& Kamat, P. V. (2013). CuInS2-sensitized quantum dot solar cell. Electrophoretic deposition, excited-state dynamics, and photovoltaic performance. The Journal of Physical Chemistry Letters, 4(5), 722-729.

[16] Panthani, M. G., Stolle, C. J., Reid, D. K., Rhee, D. J., Harvey, T. B., Akhavan, V. A., ... \& Korgel, B. A. (2013). CuInSe2 quantum dot solar cells with high open-circuit voltage. The Journal of Physical Chemistry Letters, 4(12), 2030-2034.

[17] Santra, P. K., \& Kamat, P. V. (2013). Tandem-layered quantum dot solar cells: tuning the photovoltaic response with luminescent ternary cadmium chalcogenides. Journal of the American Chemical Society, 135(2), 877-885. 
[18] McDaniel, H., Fuke, N., Pietryga, J. M., \& Klimov, V. I. (2013). Engineered CuInSe x S2-x Quantum Dots for Sensitized Solar Cells. The Journal of Physical Chemistry Letters, 4(3), 355-361.

[19] Semonin, O. E., Luther, J. M., Choi, S., Chen, H. Y., Gao, J., Nozik, A. J., \& Beard, M. C. (2011). Peak external photocurrent quantum efficiency exceeding $100 \%$ via MEG in a quantum dot solar cell. Science, 334(6062), 1530-1533.

[20] Stolle, C. J., Harvey, T. B., Pernik, D. R., Hibbert, J. I., Du, J., Rhee, D. J., ... \& Korgel, B. A. (2014). Multiexciton solar cells of CuInSe2 nanocrystals. The Journal of Physical Chemistry Letters, 5(2), 304-309.

[21]Lan, X., Masala, S., \& Sargent, E. H. (2014). Charge-extraction strategies for colloidal quantum dot photovoltaics. Nature materials, 13(3), 233-240.

[22]Zhao, K., Pan, Z., Mora-Seró, I., Cánovas, E., Wang, H., Song, Y., ... \& Zhong, X. (2015). Boosting Power Conversion Efficiencies of Quantum-Dot-Sensitized Solar Cells Beyond 8\% by Recombination Control. Journal of the American Chemical Society, 137(16), 5602-5609.

[23] McDaniel, H., Fuke, N., Makarov, N. S., Pietryga, J. M., \& Klimov, V. I. (2013). An integrated approach to realizing high-performance liquid-junction quantum dot sensitized solar cells. Nature communications, 4.

[24]Lan, X., Masala, S., \& Sargent, E. H. (2014). Charge-extraction strategies for colloidal quantum dot photovoltaics. Nature materials, 13(3), 233-240.

[25] Seo, M. H., Hwang, W. P., Kim, Y. K., Lee, J. K., \& Kim, M. R. (2011, June). Improvement of quantum dot-sensitized solar cells based on Cds and CdSe quantum dots. In Photovoltaic Specialists Conference (PVSC), 2011 37th IEEE(pp. 002652-002655). IEEE.

[26] Abbas, M. A., Basit, M. A., Park, T. J., \& Bang, J. H. (2015). Enhanced performance of PbSsensitized solar cells via controlled successive ionic-layer adsorption and reaction. Physical Chemistry Chemical Physics, 17(15), 9752-9760.

[27] Kim, J., Choi, H., Nahm, C., Moon, J., Kim, C., Nam, S., ... \& Park, B. (2011). The effect of a blocking layer on the photovoltaic performance in CdS quantum-dot-sensitized solar cells. Journal of Power Sources, 196(23), 10526-10531.

[28]Meng, K., Surolia, P. K., Byrne, O., \& Thampi, K. R. (2014). Efficient CdS quantum dot sensitized solar cells made using novel $\mathrm{Cu} 2 \mathrm{~S}$ counter electrode.Journal of Power Sources, 248, 218-223. 
[29] Du, Z., Zhang, H., Bao, H., \& Zhong, X. (2014). Optimization of $\mathrm{TiO}_{2}$ photoanode films for highly efficient quantum dot-sensitized solar cells. Journal of Materials Chemistry A, 2(32), 13033-13040.

[30] Shen, Q., Kobayashi, J., Diguna, L. J., \& Toyoda, T. (2008). Effect of ZnS coating on the photovoltaic properties of CdSe quantum dot-sensitized solar cells. Journal of Applied Physics, 103(8), 084304.

[31] Kang, J. S., Park, M. A., Kim, J. Y., Park, S. H., Chung, D. Y., Yu, S. H., ... \& Sung, Y. E. (2015). Reactively sputtered nickel nitride as electrocatalytic counter electrode for dye-and quantum dot-sensitized solar cells. Scientific reports, 5.

[32] Mora-Sero, I., Gimenez, S., Fabregat-Santiago, F., Gomez, R., Shen, Q., Toyoda, T., \& Bisquert, J. (2009). Recombination in quantum dot sensitized solar cells. Accounts of chemical research, 42(11), 1848-1857.

[33] Choi, H., Kim, J., Nahm, C., Kim, C., Nam, S., Kang, J., \& Park, B. (2013). The role of $\mathrm{ZnO}$-coating-layer thickness on the recombination in $\mathrm{CdS}$ quantum-dot-sensitized solar cells. Nano Energy, 2(6), 1218-1224.

[34] Yang, L., McCue, C., Zhang, Q., Uchaker, E., Mai, Y., \& Cao, G. (2015). Highly efficient quantum dot-sensitized $\mathrm{TiO} 2$ solar cells based on multilayered semiconductors (ZnSe/CdS/CdSe). Nanoscale, 7(7), 3173-3180.

[35]Zheng, K., Zidek, K., Abdellah, M., Zhang, W., Chabera, P., Lenngren, N., ... \& Pullerits, T. (2014). Ultrafast Charge Transfer from CdSe Quantum Dots to p-Type NiO: Hole Injection vs Hole Trapping. The Journal of Physical Chemistry C, 118(32), 18462-18471.

[36] Jiao, S., Shen, Q., Mora-Seró, I., Wang, J., Pan, Z., Zhao, K., ... \& Bisquert, J. (2015). Band Engineering in Core/Shell ZnTe/CdSe for Photovoltage and Efficiency Enhancement in Exciplex Quantum Dot Sensitized Solar Cells. ACS nano, 9(1), 908-915.

[37] Bora, T., Kyaw, H. H., \& Dutta, J. (2012). Zinc oxide-zinc stannate core-shell nanorod arrays for CdS quantum dot sensitized solar cells. Electrochimica Acta, 68, 141-145.

[38] González-Pedro, V., Xu, X., Mora-Sero, I., \& Bisquert, J. (2010). Modeling high-efficiency quantum dot sensitized solar cells. ACS nano, 4(10), 5783-5790.

[39]Chang, J. Y., Su, L. F., Li, C. H., Chang, C. C., \& Lin, J. M. (2012). Efficient "green" quantum dot-sensitized solar cells based on $\mathrm{Cu} 2 \mathrm{~S}-\mathrm{CuInS} 2-\mathrm{ZnSe}$ architecture. Chemical Communications, 48(40), 4848-4850. 
[40]Chen, C., Xie, Y., Ali, G., Yoo, S. H., \& Cho, S. O. (2011). Improved conversion efficiency of $\mathrm{CdS}$ quantum dots-sensitized $\mathrm{TiO} 2$ nanotube array using $\mathrm{ZnO}$ energy barrier layer. Nanotechnology, 22(1), 015202.

[41]Zhou, R., Niu, H., Zhang, Q., Uchaker, E., Guo, Z., Wan, L., ... \& Cao, G. (2015). Influence of deposition strategies on CdSe quantum dot-sensitized solar cells: a comparison between successive ionic layer adsorption and reaction and chemical bath deposition. Journal of Materials Chemistry A.

[42] Tvrdy, K., Frantsuzov, P. A., \& Kamat, P. V. (2011). Photoinduced electron transfer from semiconductor quantum dots to metal oxide nanoparticles.Proceedings of the National Academy of Sciences, 108(1), 29-34.

[43] Chakrapani, V., Baker, D., \& Kamat, P. V. (2011). Understanding the Role of the Sulfide Redox Couple (S2-/S n 2-) in Quantum Dot-Sensitized Solar Cells.Journal of the American Chemical Society, 133(24), 9607-9615.

[44]Tian, J., \& Cao, G. (2013). Semiconductor quantum dot-sensitized solar cells. Nano reviews, 4.

[45] Sung, S. D., Lim, I., Kim, M. S., \& Lee, W. I. (2013). Effect of Ultrathin Al2O3 Layer on TiO2 Surface in CdS/CdSe Co-Sensitized Quantum Dot Solar Cells.BULLETIN OF THE KOREAN CHEMICAL SOCIETY, 34(2), 411-414.

[46]Rao, S. S., Durga, I. K., Gopi, C. V., Tulasivarma, C. V., Kim, S. K., \& Kim, H. J. (2015). The effect of TiO 2 nanoflowers as a compact layer for CdS quantum-dot sensitized solar cells with improved performance. Dalton Transactions, 44(28), 12852-12862.

[47] Tachibana, Y., Umekita, K., Otsuka, Y., \& Kuwabata, S. (2008). Performance improvement of CdS quantum dots sensitized $\mathrm{TiO} 2$ solar cells by introducing a dense $\mathrm{TiO} 2$ blocking layer. Journal of Physics D: Applied Physics, 41(10), 102002.

[48] Meng, K., Surolia, P. K., Byrne, O., \& Thampi, K. R. (2015). Quantum dot and quantum dotdye co-sensitized solar cells containing organic thiolate-disulfide redox electrolyte. Journal of Power Sources, 275, 681-687.

[49]Lee, Y. L., Huang, B. M., \& Chien, H. T. (2008). Highly efficient CdSe-sensitized TiO2 photoelectrode for quantum-dot-sensitized solar cell applications. Chemistry of Materials, 20(22), 6903-6905. 
[50] Kamat, P. V. (2008). Quantum dot solar cells. Semiconductor nanocrystals as light harvesters $\dagger$. The Journal of Physical Chemistry C, 112(48), 18737-18753.

[51] Chettiar, U. K., \& Engheta, N. (2012). Internal homogenization: Effective permittivity of a coated sphere. Optics express, 20(21), 22976-22986.

[52] Shevarenkov, D. N., \& Shchurov, A. F. (2006). Dielectric properties of polycrystalline ZnS. Semiconductors, 40(1), 33-35.

[53] Chin, A., Liao, C. C., Lu, C. H., Chen, W. J., \& Tsai, C. (1999, June). Device and reliability of high-k Al/sub 2/O/sub 3/gate dielectric with good mobility and low D/sub it. In VLSI Technology, 1999. Digest of Technical Papers. 1999 Symposium on (pp. 135-136). IEEE.

[54]Brus, L. (1986). Electronic wave functions in semiconductor clusters: experiment and theory. The Journal of Physical Chemistry, 90(12), 2555-2560.

[55]Lunz, U., Kuhn, J., Goschenhofer, F., Schüssler, U., Einfeldt, S., Becker, C. R., \& Landwehr, G. (1996). Temperature dependence of the energy gap of zinc-blende CdSe and Cd1xZnxSe epitaxial layers. Journal of applied physics,80(12), 6861-6863.

[56] Jeong, T. S., Yu, P. Y., \& Kim, T. S. (2000). Temperature dependence of the free excitons in a CdS single crystal.

[57] Caglar, M., Caglar, Y., Aksoy, S., \& Ilican, S. (2010). Temperature dependence of the optical band gap and electrical conductivity of sol-gel derived undoped and $\mathrm{Li}$-doped $\mathrm{ZnO}$ films. Applied Surface Science, 256(16), 4966-4971.

[58] Varshni, Y. P. (1967). Temperature dependence of the energy gap in semiconductors. Physica, 34(1), 149-154.

[59] Singh, P., \& Ravindra, N. M. (2012). Temperature dependence of solar cell performance-an analysis. Solar Energy Materials and Solar Cells, 101, 36-45.

[60] O'Donnell, K. P., \& Chen, X. (1991). Temperature dependence of semiconductor band gaps. Applied Physics Letters, 58(25), 2924-2926.

[61]Fahimi, M. J., Fathi, D., \& Ansari-Rad, M. (2015). Accurate analysis of electron transfer from quantum Dots to metal Oxides in quantum DoT sensitized solar Cells. Physica E: Lowdimensional Systems and Nanostructures. 


\section{How to cite this article:}

Fahimi M. J, Fathi D and Bastami H. Blocking layer modeling for temperature analysis of electron transfer rate in quantum dot sensitized solar cells. J. Fundam. Appl. Sci., 2016, 8(3S), 54-70. 